\title{
FINE-SCALE HABITAT USE OF REINTRODUCED BLACK-FOOTED FERRETS ON PRAIRIE DOG COLONIES IN NEW MEXICO
}

\author{
Jennifer G. Chipault ${ }^{1,6}$, Dean E. Biggins ${ }^{2}$, James K. Detling'1,3, \\ Dustin H. Long ${ }^{4}$, and Robin M. Reich ${ }^{5}$
}

\begin{abstract}
Black-footed ferrets (Mustela nigripes) are among the most endangered animals in North America. Reintroductions of captive-born ferrets onto prairie dog (Cynomys spp.) colonies are crucial to the conservation of the species. In September 2007, captive-born ferrets were released on a black-tailed prairie dog (Cynomys ludovicianus) colony at the Vermejo Park Ranch, New Mexico. Ferret kits experimentally released in areas of comparatively low and high prairie dog burrow densities were located via spotlight surveys. Some maturing ferret kits were subsequently translocated to areas of low and high burrow densities on nearby prairie dog colonies. For 2 months, fine-scale habitat use was quantified by mapping all burrow openings within a 30-m radius of each ferret location. Spatial statistics accounted for autocorrelation in the burrow densities in areas used by ferrets. It was hypothesized that ferrets would select areas of high burrow densities within colonies; however, burrow densities in areas used by ferrets were generally similar to the available burrow densities. Because ferrets used areas with burrow densities similar to densities available at the colony level and because of the potential energetic benefits for ferrets using areas with high burrow densities, releasing ferrets on colonies with high burrow densities might increase reintroduction success.
\end{abstract}

RESumen.—Los hurones de patas negras (Mustela nigripes) se encuentran entre los animales en mayor peligro en Norteamérica. Las reintroducciones de hurones criados en cautiverio a las colonias de perros llaneros (Cynomys spp.) son cruciales para la conservación de la especie. En septiembre de 2007, se liberaron hurones criados en cautiverio en una colonia de perros llaneros de cola negra (Cynomys ludovicianus) en Vermejo Park Ranch, Nuevo México. Mediante monitoreos con reflectores, se identificaron crías de hurón que se habían liberado experimentalmente en áreas con densidades comparativamente bajas y altas de madrigueras de perros llaneros. Posteriormente, se trasladó a algunos hurones que se aproximaban a la madurez sexual a áreas con densidades altas y bajas de madrigueras en colonias cercanas de perros llaneros. Durante 2 meses, se cuantificó el uso del hábitat con una escala detallada al identificar en un mapa todas las entradas de las madrigueras que había en un radio de 30 metros alrededor de donde estaba cada hurón. Al generar estadísticas espaciales pudimos explicar la autocorrelación en las densidades de madrigueras en uso. Nuestra hipótesis era que los hurones seleccionarían áreas con densidades elevadas de madrigueras dentro de las colonias; sin embargo, las densidades de las madrigueras en las áreas ocupadas por los hurones fueron generalmente similares a las densidades de las madrigueras disponibles. Debido a que las densidades de madrigueras usadas por los hurones son similares a las densidades disponibles al nivel de la colonia, y debido a los beneficios energéticos potenciales que las áreas de densidades altas de madrigueras tienen para los hurones, el liberar a los hurones en las colonias con densidades altas de madrigueras podría aumentar el éxito de su reintroducción.

Black-footed ferrets (Mustela nigripes, hereafter "ferrets") are extreme habitat specialists; prairie dogs (Cynomys spp.) comprise $\sim 90 \%$ of their diet, and ferrets inhabit prairie dog burrows (Sheets et al. 1972, Richardson et al. 1987). Prairie dogs now occupy $\sim 2 \%$ of their historic range because of habitat loss, lethal control, and plague (Miller et al. 1994, Lockhart et al. 2006). As prairie dog dependents, ferrets underwent even greater population declines during the 19th and 20th centuries and are now among the most endangered animals in North America.
Since 1991, ferret reintroductions have taken place at 19 western North American grassland sites with adequate prairie dog populations. In 2008, only 4 sites had ferret populations with at least 30 breeding adults during consecutive years (Jachowski and Lockhart 2009). Because success rates of species relocations generally are low (e.g., Griffith et al. 1989, Stamps and Swaisgood 2007), use of behavioral observations to guide future conservation practices is becoming more common in recovery efforts of rare species. For example, success of the reintroduction

\footnotetext{
${ }^{1}$ Department of Biology, Colorado State University, Fort Collins, CO 80523-1878

${ }^{2}$ U.S. Geological Survey, Fort Collins Science Center, 2150 Centre Ave., Building C, Fort Collins, CO 80526-8118.

${ }^{3}$ Natural Resource Ecology Lab, Colorado State University, Fort Collins, CO 80523-1499.

${ }^{4}$ Turner Endangered Species Fund, Box 131, Cimarron, NM 87714.

${ }^{5}$ Department of Forest, Rangeland, and Watershed Stewardship, Colorado State University, Fort Collins, CO 80523.

${ }^{6}$ E-mail: jgchipault@yahoo.com
} 
of martens (Martes americana), members of the same subfamily as ferrets, is largely attributed to advanced knowledge about habitat suitability at release sites (Slough 1994, Chapin et al. 1997).

Ferret habitat within prairie dog colonies is patchy (Biggins et al. 2006b, Jachowski et al. 2008, Chipault 2010), and understanding the influence of environmental heterogeneity on behavior of newly released ferrets may increase the effectiveness of ferret reintroductions. Evidence is mounting that wild-born ferrets select fine-scale ( $\leq 1 \mathrm{ha}$ ) areas of relatively high prairie dog burrow entrance (hereafter "burrow") densities within a prairie dog colony (Biggins et al. 1985, Biggins et al. 2006b, Jachowski 2007, Livieri 2007, Eads 2009). However, habitat selection of captive-born ferrets released in the wild is not well understood (Carlson 1993, Biggins et al. 2006b). This experiment was conducted to test predictions of ferret habitat use emanating from former studies by manipulating release locations of captive-born ferrets.

Fine-scale habitat selection by captive-born ferrets released for wild preconditioning at Vermejo Park Ranch, New Mexico (hereafter "Vermejo"), was examined. Such wild preconditioning allows naïve ferrets to adjust to the natural environment while their locations are closely monitored, thereby increasing longterm survival following recapture and transportation to permanent release sites (Vargas et al. 1998, Biggins et al. 1999). In this study, ferrets were released in areas of varied blacktailed prairie dog (Cynomys ludovicianus) burrow densities within a single colony. Based on previous findings from studies of wild-born ferrets, we hypothesized that newly released ferrets would move to areas of high burrow densities such that burrow densities in areas used by ferrets would be greater than burrow densities at release sites for ferrets placed in low density areas and that use of areas with relatively high burrow densities would be maintained by ferrets placed in areas with high burrow densities.

\section{Methods}

Captive-born ferret kits obtained from the National Black-footed Ferret Conservation Center in northern Colorado were released on a prairie dog colony in New Mexico and subsequently monitored. After 2-4 weeks in the wild, some of these kits were translocated to other nearby prairie dog colonies so that all maturing ferrets had enough space to establish individual territories. Monitoring of all ferrets continued for a total of 2 months. Two data sets (pretranslocation and posttranslocation) of quantified habitat use were established by mapping fine-scale prairie dog burrow densities in the field. Available habitat was quantified digitally. Methodological details for each portion of this study follow.

\section{Study Area}

Vermejo is a privately owned ranch in Colfax County, northern New Mexico. Approximately 24,000 ha of Vermejo is contiguous, semiarid shortgrass prairie dominated by blue grama (Bouteloua gracilis). In 2007, Vermejo had 48 black-tailed prairie dog colonies totaling 2031 ha and ranging in size from 1 to 416 ha (D.H. Long unpublished data).

Pretranslocation Ferret Locations

In September 2007, 6 captive-born ferret families (26 individuals) were released on a 416-ha prairie dog colony (named Phoneline) for wild preconditioning (Table 1, Fig. 1). Each family consisted of a dam and her kits. Three families were released in areas of relatively high prairie dog burrow densities (high-release treatment), and 3 were released in areas of relatively low burrow densities (low-release treatment; Table 1). Families were randomly assigned to a burrow density category and specific release site. Six male kits and 4 female kits were released in each burrow density category.

Release sites were predetermined by searching for obvious high and low burrow density areas and then quantifying burrow densities within a $30-\mathrm{m}$ radius $(0.28 \mathrm{ha})$ of the release burrow (Table 1). This plot size was within the range of other fine-scale burrow density studies of captive-born ferrets: 0.07 ha in Biggins et al. (2006b) and 1 ha in Carlson (1993). Burrows within plots were recorded using a Trimble ${ }^{\circledR}$ GPS Pathfinder ${ }^{\circledR}$ Pro XRS receiver with 1-m accuracy. Release sites were dispersed across the colony to decrease the probability of family territories overlapping (Fig. 1). Ferrets were released in active prairie dog burrows that were not connected to other burrow entrances as determined by using smoke generators and a leaf blower. Aboveground retention pens $(\sim 120 \times 90 \times 60 \mathrm{~cm})$ were placed over 
TABLE 1. Six black-footed ferret (Mustela nigripes) family groups (A-F) released on the Phoneline colony on 4 September 2007 at the Vermejo Park Ranch, New Mexico. Studbook numbers were given to each ferret at the National Black-footed Ferret Conservation Center, Colorado. Each family group of kits was released with a dam that was 2-3 years old. Release and translocation densities (burrows $\cdot \mathrm{ha}^{-1}$ ) are based on counts of black-tailed prairie dog (Cynomys ludovicianus) burrows within circular plots with $30-\mathrm{m}$ radii $(0.28 \mathrm{ha})$ centered on the ferret release/translocation burrow. Ferrets listed as recaptured were recovered by the end of the wild preconditioning period (6 November).

\begin{tabular}{|c|c|c|c|c|c|}
\hline $\begin{array}{l}\text { Family } \\
\text { letter }\end{array}$ & $\begin{array}{l}\text { Studbook } \\
\text { number }\end{array}$ & Sex & $\begin{array}{l}\text { Release burrow } \\
\text { density (category) }\end{array}$ & $\begin{array}{l}\text { Translocation } \\
\text { colony }\end{array}$ & $\begin{array}{r}\text { Translocation burrow } \\
\text { density (category) }\end{array}$ \\
\hline $\bar{A}$ & $\begin{array}{l}5686^{\mathrm{a}} \\
5687 \\
5688^{\mathrm{a}} \\
5689\end{array}$ & $\begin{array}{c}\mathrm{M} \\
\mathrm{M} \\
\mathrm{M} \\
\mathrm{F}\end{array}$ & $\begin{array}{l}109.6 \text { (high) } \\
109.6 \text { (high) } \\
109.6 \text { (high) } \\
109.6 \text { (high) }\end{array}$ & $\begin{array}{c}\text { Windmill } \\
99-4 \\
99-5 \\
-\end{array}$ & $\begin{array}{c}106.1 \text { (low) } \\
92.0 \text { (low) } \\
109.6 \text { (high) } \\
\text { _ }\end{array}$ \\
\hline B & $\begin{array}{l}5676^{\mathrm{b}, \mathrm{c}} \\
5677\end{array}$ & $\begin{array}{l}\mathrm{M} \\
\mathrm{M}\end{array}$ & $\begin{array}{l}60.1 \text { (low) } \\
60.1 \text { (low) }\end{array}$ & $\begin{array}{c}\text { Drift } \\
-\end{array}$ & N/A (high) \\
\hline $\mathrm{C}$ & $\begin{array}{l}5700 \\
5701 \\
5702\end{array}$ & $\begin{array}{l}\mathrm{M} \\
\mathrm{M} \\
\mathrm{M}\end{array}$ & $\begin{array}{l}102.6 \text { (high) } \\
102.6 \text { (high) } \\
102.6 \text { (high) }\end{array}$ & $\begin{array}{c}\text { Drift } \\
\text { Windmill } \\
-\end{array}$ & $\begin{array}{c}49.5 \text { (low) } \\
137.9 \text { (high) } \\
\text { _ }\end{array}$ \\
\hline $\mathrm{D}$ & $\begin{array}{l}5738 \\
5739 \\
5740^{\mathrm{a}, \mathrm{c}}\end{array}$ & $\begin{array}{l}\mathrm{M} \\
\mathrm{M} \\
\mathrm{M}\end{array}$ & $\begin{array}{l}53.1 \text { (low) } \\
53.1 \text { (low) } \\
53.1 \text { (low) }\end{array}$ & $\begin{array}{c}99-4 \\
- \\
-\end{array}$ & $\begin{array}{c}127.3 \text { (high) } \\
- \\
-\end{array}$ \\
\hline $\mathrm{E}$ & $\begin{array}{l}5788 \\
5789^{\mathrm{c}} \\
5790^{\mathrm{a}, \mathrm{c}} \\
5792^{\mathrm{c}} \\
5793\end{array}$ & $\begin{array}{l}\mathrm{F} \\
\mathrm{F} \\
\mathrm{F} \\
\mathrm{M} \\
\mathrm{F}\end{array}$ & $\begin{array}{l}63.7 \text { (low) } \\
63.7 \text { (low) } \\
63.7 \text { (low) } \\
63.7 \text { (low) } \\
63.7 \text { (low) }\end{array}$ & $\begin{array}{c}\text { Drift } \\
- \\
- \\
\text { Drift }\end{array}$ & $\begin{array}{c}95.5 \text { (high) } \\
- \\
- \\
53.1 \text { (low) }\end{array}$ \\
\hline $\mathrm{F}$ & $\begin{array}{l}5759 \\
5760^{\mathrm{c}} \\
5761\end{array}$ & $\begin{array}{l}\mathrm{F} \\
\mathrm{F} \\
\mathrm{F}\end{array}$ & $\begin{array}{l}99.0 \text { (high) } \\
99.0 \text { (high) } \\
99.0 \text { (high) }\end{array}$ & $\begin{array}{c}\text { Windmill } \\
\text { Windmill }\end{array}$ & $\begin{array}{c}127.3 \text { (high) } \\
67.2 \text { (low) }\end{array}$ \\
\hline
\end{tabular}

aDisappeared (temporarily or permanently) without independent locations logged; no locations from these ferrets in the pretranslocation data set.

bDisappeared immediately after translocation; no locations from this ferret in the posttranslocation data set.

cNot recaptured at end of preconditioning period.

each release burrow entrance to facilitate a soft-release (Long et al. 2006). Ferrets were placed into the 6 retention pens on 2 September 2007. On 4 September, retention pens were removed and ferrets were allowed to disperse freely. The kits were an average of 85.4 days old $(n=20, \mathrm{SE}=1.0$, range 79-91 days old).

Ferrets were monitored via spotlight surveys (Biggins et al. 2006a) using a high-intensity spotlight (500,000-730,000 candlepower) from an all-terrain vehicle (ATV) or minitruck. Search patterns were not predetermined, but observers tended to follow 2-track roads through colonies, departing from roads to view areas otherwise not visible. Surveys were conducted on 61 nights, usually by one observer per night. Monitoring was performed irregularly from dusk until dawn depending on animal activity levels and weather, with an estimated average of 6-7 hours of monitoring per night. Passive integrated transponder (PIT) tags were implanted into each ferret before release. After a ferret was detected in the wild via eyeshine, a circular antenna of the transponder scanner was placed on the burrow opening into which the ferret submerged; when the ferret exited the burrow, the unique number encoded in the PIT tag registered (Fagerstone and Johns 1987). The locations at which ferrets were first spotted were recorded with a GPS unit.

\section{Posttranslocation Ferret Locations}

Because estimates of ferret home ranges are $\sim 75$ ha for females and $\sim 150$ ha for males (Biggins et al. 1985, Jachowski 2007, Livieri 2007), the Phoneline colony was likely not large enough to support territories for all surviving kits. Therefore, when dispersing kits were observed during 18 September-1 October, they were captured and translocated to predetermined locations on 4 other Vermejo prairie dog colonies (named 99-4, 99-5, Drift, and Windmill; Table 1, Fig. 1) to decrease risk of mortality during dispersal (Biggins et al. 1999).

The ferret translocation colonies ranged from 54 to 262 ha (D.H. Long unpublished data). Ferret translocation sites were preselected in the same manner as release sites. This allowed 


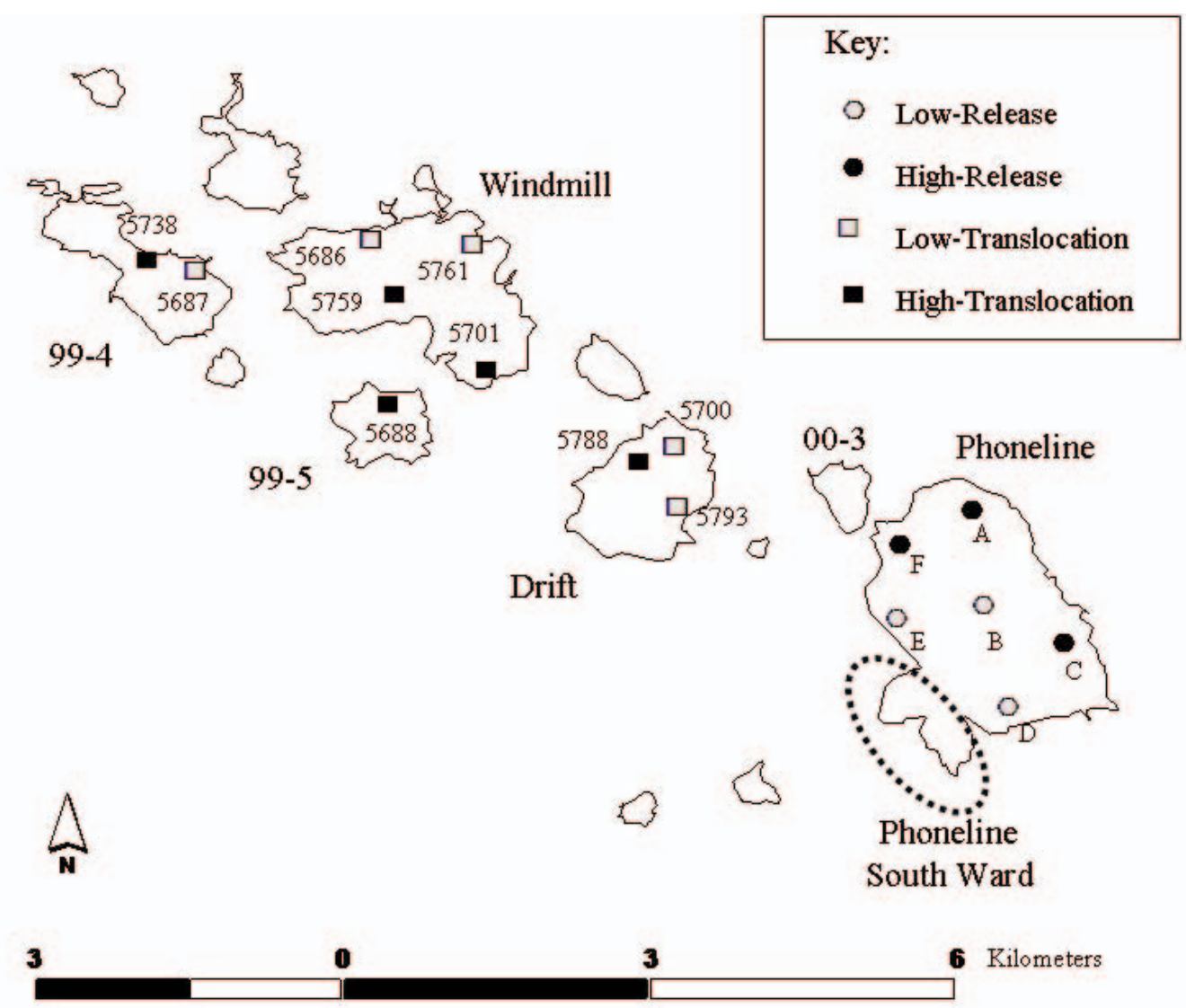

Fig. 1. Black-footed ferret (Mustela nigripes) release sites (6) on Phoneline colony, and kit translocation sites (10) on 99-4, 99-5, Drift, and Windmill colonies, Vermejo Park Ranch, New Mexico, 2007. Sites were categorized as high or low based on prairie $\operatorname{dog}$ (Cynomys ludovicianus) burrow density (burrows $\cdot \mathrm{ha}^{-1}$ ) at a 0.28 -ha scale. Ferret family letters and kit stud numbers (Table 1) are indicated next to release and translocation sites, respectively. Colonies 00-3 and Phoneline South Ward (indicated by dashed oval) are included because ferrets dispersed to these colonies.

another experimental manipulation of the burrow densities in areas where ferrets were placed. The first dispersing kit trapped from a family was translocated to an area with the opposite fine-scale burrow density category as its Phoneline release site; a second kit from that family was moved to an area with the same density category as its release site; and a third kit trapped in a family was moved to an area with the opposite density category as its release. Four kits from different families (Table 1) were randomly selected to remain on the Phoneline colony. Data from locations of these kits were maintained in the pretranslocation data set because an experimental translocation was not part of the behavioral history of these 4 ferrets. Monitoring of all ferrets continued via nightly spotlight surveys during and after the translocation of kits. At the conclusion of the study, 14 ferret kits were recaptured (Table 1) and transported to Arizona for permanent release. The remaining 6 kits were presumed dead (Table 1; Chipault 2010).

\section{Prairie Dog Burrow Densities in Areas Used by Ferrets}

GPS locations were recorded of all prairie dog burrow openings in a 30-m-radius plot centered on each independent kit location. The circular plots were allowed to overlap (Biggins et al. 2006b). Burrow mapping was completed within 4 days of each ferret observation.

Locations of mapped burrows were viewed with ArcView ${ }^{\mathrm{TM}}$ Geographic Information System (GIS), version 3.1. Plots not fully within 2007 colony boundaries were removed from the 
data set because portions off-colony did not represent ferret habitat (Biggins et al. 2006b). Counts of burrow openings in these plots were converted to densities (burrows $\cdot \mathrm{ha}^{-1}$; hereafter "used burrow densities") for analyses.

Prairie Dog Burrow Densities

in Areas Available to Ferrets

Georeferenced 2005 satellite imagery with $1-m$ resolution was used to estimate burrow densities for areas-prairie dog colonies or wards - available to ferrets (hereafter "available burrow densities”; Biggins et al. 2006d). Wards are portions of colonies separated by a physical barrier from the rest of the colony (Hoogland 1995). Because a railroad grade divides the Phoneline colony, the main ward will be referred to as the Phoneline colony and the small, southernmost ward as Phoneline South Ward (Fig. 1). Available burrow densities were compared to used burrow densities on each colony or ward inhabited by ferret kits (Biggins et al. 2006b).

Because prairie dog colonies on Vermejo are young and dynamic, and because not all burrows can be visually detected in satellite images, the 2005 satellite images needed to be adjusted to 2007 burrow densities determined in the field. Using GIS, circular plots of 30-m radii were created around ferret locations recorded in 2007. Circular plots completely within the 2005 colony boundaries (D.H. Long unpublished data) were used for calibration $(n$ $=81$ ). The percentages of the 2005 colonies used for calibration ranged from $2.5 \%$ to $5.1 \%$. Within the circular plots, a point was added to a GIS layer over every light-colored area on the 2005 image that resembled a burrow mound (Biggins et al. 2006d). The total number of burrow mounds counted and the total area covered by plots for each colony were determined and compared to the densities of burrows mapped in the field in 2007 in those same areas. The percent increase or decrease between 2005 satellite-based and 2007 fieldbased burrow density (burrows $\cdot \mathrm{ha}^{-1}$ ) for each colony was calculated, and correction factors ranged from $-31.7 \%$ to $+65.2 \%$.

To estimate available burrow densities on colonies in 2007, 5 random locations for each independent kit location were generated within corresponding 2005 colony or ward boundaries (Cooper and Millspaugh 2001). Random locations were manually moved to the nearest burrow mound on the satellite image. Plots with $30-\mathrm{m}$ radii were created around these burrow-centered locations; overlap of plots was allowed (Biggins et al. 2006b). At least 5\% of each colony was sampled, as recommended by Biggins et al. (1993); the number of locations per colony ranged from 15 to 175 . A GIS layer was created that consisted of points within these plots that were over burrow mounds on the satellite image. The density of available burrows on each 2005 colony or ward was calculated and then the corresponding correction factor was applied to estimate 2007 available burrow density.

\section{Statistical Analyses}

Program R was used for analyses, with a probability of committing a type I error $(\alpha)$ set at 0.10 for checking statistical assumptions and 0.05 for statistical testing. A location was used as the sampling unit. Only locations of kits that had become independent of their family units were used in analyses. Assumptions regarding burrow patchiness, static burrow densities over short timespans, correlations between burrow and prairie dog densities, and biological and temporal independence of ferret locations were assessed to appropriately analyze and interpret ferret habitat use (Chipault 2010).

The assumption of spatial independence of ferret-used locations (e.g., Lichstein et al. 2002, Hoeting 2009) was assessed with Moran's I statistic (Moran 1950). If Moran's I statistics under normal approximation indicated spatial dependence, then we ran spatially explicit $t$ tests (instead of classical $t$ tests). These tests use weight matrices (Bonham and Reich 1999, Reich and Bonham 2001) based on inverse distances between all ferret-used locations to account for distances between ferret-used locations predicting some of the variation in fine-scale burrow densities (i.e., ferret-used locations closer together are more likely to have similar burrow densities than ferret-used locations farther apart). For nonnormal data with spatial autocorrelation, a Wilcoxon's rank sum test was performed on the residuals from a spatial autoregressive model with intercept only.

One-sample $t$ tests were performed to determine if there was a change from release or translocation burrow densities to used burrow densities; change was calculated by subtracting the burrow density at a ferret's release/translocation site from the ferret's used burrow 
density. Two-sample, unpaired $t$ tests were performed to compare the used burrow densities of the high and low burrow density treatment groups in each data set. One-sample $t$ tests were performed on the differences of available burrow densities from used burrow densities on each colony. Normality was checked using Shapiro tests and equality of variances was checked using Levene's tests. One-way analysis of variance (ANOVA) and subsequent Tukey's HSD tests were performed to compare used burrow densities among colonies. Spatially-explicit ANOVAs were accomplished via spatial autoregressive models with dummy variables. Residuals were checked for normality and homoscedasticity.

\section{RESUlts}

\section{Pretranslocation Ferret Locations}

Forty-six locations were obtained for 16 ferrets (range 1-8 locations per ferret; $\bar{x}=5.4$ locations per ferret, $\mathrm{SE}=0.6)$, resulting in 985 mapped prairie dog burrows in the pretranslocation data set (range 38.9-102.6 burrows $\cdot$ ha $^{-1}$ at ferret-used locations; $\bar{x}=75.9$ burrows $\cdot \mathrm{ha}^{-1}, \mathrm{SE}=2.2$ ). Because sex (males: $n=23$; females: $n=23$ ) did not predict used burrow densities $(P \geq 0.50)$, treatment groups were not separated by sex for further analyses. Locations on 2 colonies (named Drift and 00-3; Fig. 1) were included in this data set because 2 ferrets that were released on the Phoneline colony subsequently dispersed to these colonies. Spatial autocorrelation in used burrow densities was not significant for the data set as a whole, nor for the treatment groups separately (Moran's I, low-release: $n=25$; highrelease: $n=21, P \geq 0.39$ ).

The change from release burrow densities to used burrow densities was significant for both treatment groups, with ferrets released in low burrow density areas using areas with greater burrow densities, and those released in areas with high burrow densities using areas with lower burrow densities (one-sample $t$ test, low-release: $n=25$, mean of the differences $=13.3$ burrows $\cdot \mathrm{ha}^{-1}, \mathrm{SE}=3.1, t=4.25, P<$ 0.001 ; one-sample $t$ test, high-release: $n=21$, mean of the differences $=-25.4$ burrows $\cdot \mathrm{ha}^{-1}$, $\mathrm{SE}=3.5, t=-7.30, P<0.001$; Fig. 2). A difference in the used burrow densities of highand low-release ferrets was not detected $(P=$ 0.17; Fig. 2).
No significant differences in used and available burrow densities were found on the Drift and 00-3 colonies (Drift: $n=5, P=0.98$; 00-3: $n=6, P=0.12$ ), but used burrow densities were slightly lower than available burrow densities on the Phoneline colony (one-sample $t$ test: $n=35$, mean of differences $=-8.6$ burrows . $\mathrm{ha}^{-1}, \mathrm{SE}=2.5, t=-3.47, P=0.001$; Fig. 3). Used burrow densities did not differ among colonies (one-way ANOVA: $n=46, P=0.86$ ).

\section{Posttranslocation Ferret Locations}

Fifty-three locations were obtained for 10 ferret kits (range 2-10 locations per ferret, $\bar{x}$ $=5.3$ locations per ferret, $\mathrm{SE}=1.7$ ) subsequent to their translocation to other colonies, resulting in 1501 mapped prairie dog burrows in the posttranslocation data set (range 35.4-187.5 burrows $\cdot \mathrm{ha}^{-1}$ at ferret-used locations; $\bar{x}=100.2$ burrows $\cdot \mathrm{ha}^{-1}, \mathrm{SE}=4.3$ ). Again, sex (males: $n=31$; females: $n=22$ ) did not predict used burrow densities $(P \geq 0.58)$, so treatment groups were not separated by sex in further analyses. In addition to the 4 colonies (99-4, 99-5, Drift, and Windmill; Fig. 1) to which ferrets were translocated, locations on Phoneline South Ward were included in this data set because a ferret that was translocated to the Drift colony later dispersed to that ward.

Burrow densities used by low-translocation ferrets were inversely transformed to normalize the data and to enhance the detectability of spatial autocorrelation (Czaplewski et al. 1994). Spatial autocorrelation in used burrow densities was significant for the posttranslocation data set as a whole (Moran's $I, I=0.41$, $z$ $=9.18, P<0.001)$, as well as for both treatment groups separately (low-translocation: $n=$ $25, I=0.18, z=2.43, P=0.02$; high-translocation: $n=28, I=0.33, z=4.82, P<0.001$ ). Gaussian spatial autoregressive models with only intercepts revealed that spatial dependency explained $4.5 \%$ of the variation in the used burrow densities for the data set as a whole, and $76.8 \%$ and $37.3 \%$ for low- and high-translocation data, respectively. Thus, spatial autocorrelation was stronger within the data subsets than within the posttranslocation data set as a whole (Lichstein et al. 2002).

As occurred within the pretranslocation data set, the change from translocation burrow densities to ferret-used densities was significant for both treatment groups in the posttranslocation data set, with low-translocation 


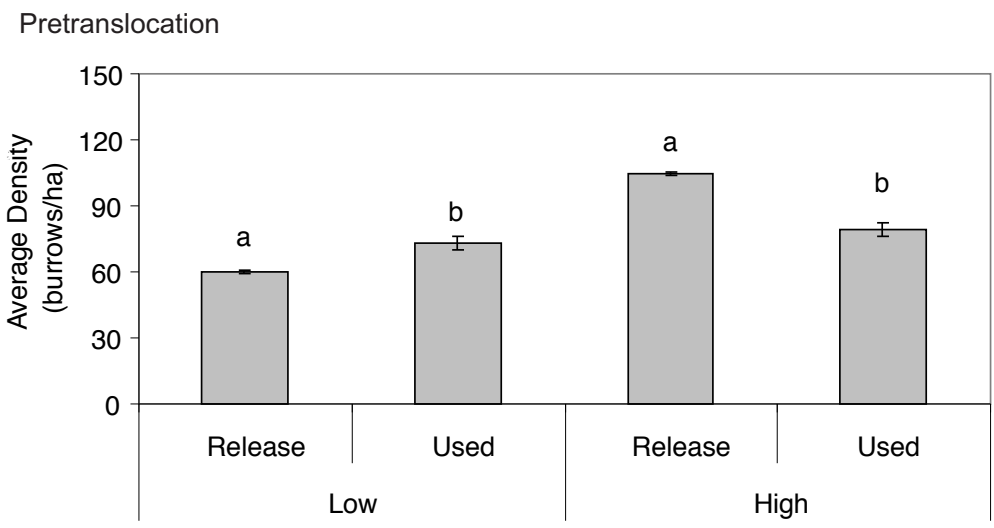

Posttranslocation

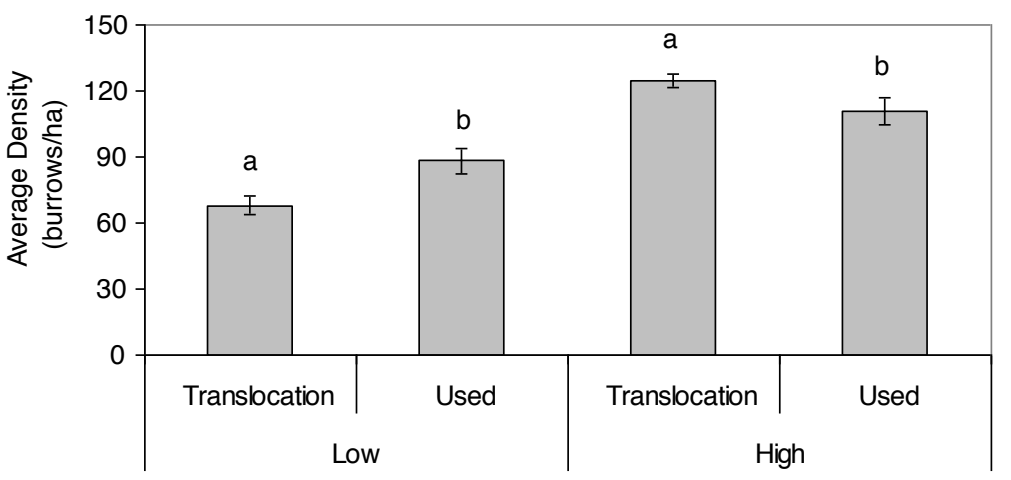

Fig. 2. Average prairie dog (Cynomys ludovicianus) burrow densities at release or translocation sites for black-footed ferrets (Mustela nigripes) placed in low (pretranslocation: $n=25$; posttranslocation: $n=25$ ) and high (pretranslocation: $n=21$; posttranslocation: $n=28$ ) burrow densities compared to average used burrow densities for those same ferrets, Vermejo Park Ranch, New Mexico, 2007. Within either the low or high burrow density category, different letters above bars indicate significant differences $(P \leq 0.008)$. The same letters above "used" bars indicate similarities in densities $(P \geq 0.17)$. Error bars represent standard error.

ferrets using areas with higher burrow densities and high-translocation ferrets using areas with lower burrow densities (spatial one-sample $t$ tests, low-translocation: $n=25$, mean of the differences $=20.3$ burrows $\cdot \mathrm{ha}^{-1}, \mathrm{SE}=$ 5.8, $t=3.18, P=0.004$; high-translocation: $n$ $=28$, mean of the differences $=-13.9$ burrows $\cdot \mathrm{ha}^{-1}, \mathrm{SE}=4.6, t=-2.86, P=0.008$; Fig. 2). The used burrow densities of hightranslocation ferrets were not significantly different from the used densities of low-translocation ferrets after accounting for spatial autocorrelation with a Wilcoxon's rank sum test on residuals from a spatial autoregressive model with intercept only $(n=53, P=0.86$; Fig. 2$)$.

Used and available burrow densities did not appear to differ significantly on any colony (Phoneline South Ward: $n=3, P=0.20$; Drift: $n=15, P=0.75$; colony 99-4: $n=9, P=0.08$; colony 99-5: $n=3, P=0.17$; Windmill: $n=$ 23, $P=0.26$; Fig. 3). Used burrow densities differed among colonies when tested with a spatial autoregressive model with colonies as categories $\left(n=53, F_{5,47}=30.07, P<0.001\right)$; Windmill colony $(n=23)$ had significantly higher used burrow densities than Phoneline South Ward $(n=3$; Tukey's HSD test: $P<$ $0.001)$, Drift $(n=15 ; P<0.001)$, and colony 99-4 $(n=9 ; P<0.001)$, while colony 99-5 $(n$ $=3$ ) had higher used burrow densities than Phoneline South Ward ( $P=0.04$; Fig. 3).

\section{DISCUSSION}

Contrary to our hypotheses, captive-born black-footed ferret kits released at Vermejo 


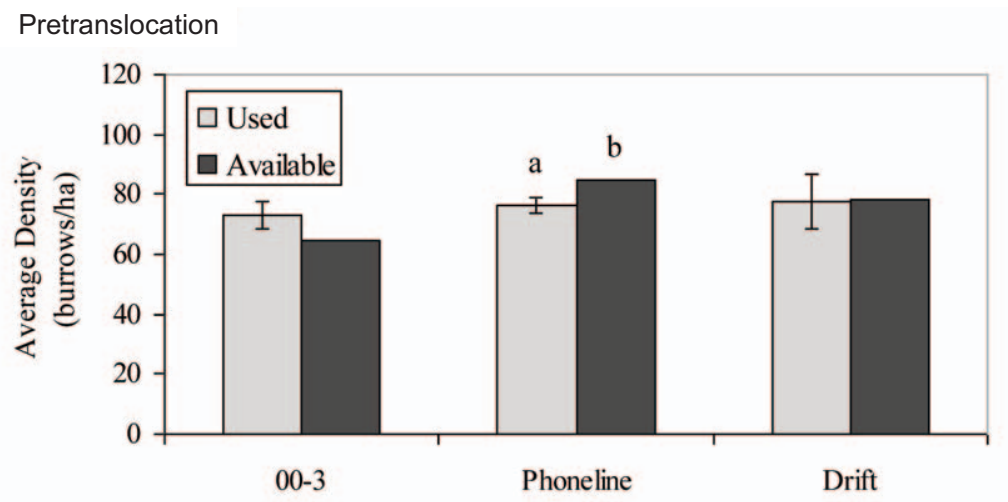

Posttranslocation

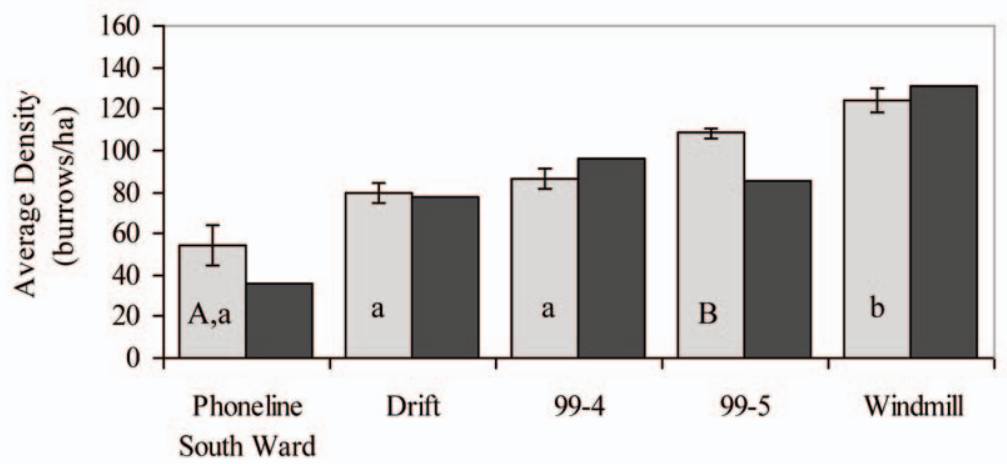

Colony of Location

Fig 3. Average used prairie dog (Cynomys ludovicianus) burrow densities for each colony on which black-footed ferrets (Mustela nigripes) were located pre- and posttranslocation, and the available burrow densities at those colonies, Vermejo Park Ranch, New Mexico, 2007. Within each colony, different letters above bars indicate significant differences $(P=0.001)$. Among colonies, different letters within grey bars indicate significant differences in used burrow densities, with capital and lowercase letters representing different comparisons $(P \leq 0.04)$. Error bars represent standard error.

Park Ranch did not select the densest areas of black-tailed prairie dog burrows within a colony. Instead, they used areas with burrow densities approximating those available on the colony that they inhabited (Fig. 3). However, consistent with our predictions, ferrets released in areas of low burrow density did select areas of higher burrow densities, even if those densities were only average for the colony.

Use of average burrow densities possibly was due to available burrow densities being greater than some threshold of prey or refugia density required by ferrets (e.g., 10 burrows • $\mathrm{ha}^{-1}$ based on observations, Forrest et al. 1985; 12 active burrows $\cdot \mathrm{ha}^{-1}$ based on ferret energy requirements, Biggins et al. 1993). Perhaps selection of high fine-scale burrow densities by captive-born kits released into habitat free of conspecifics in a previous study (Biggins et al. 2006b) can be explained, in part, by available burrow densities in that study being lower than those at Vermejo. However, Carlson (1993) reported captive-born ferrets using average burrow densities on white-tailed prairie dog (Cynomys leucurus) colonies with estimated densities less than those at Vermejo. Furthermore, wild-born ferrets selected for dense burrows even within colonies of relatively high available burrow densities (Biggins et al. 1985, Jachowski 2007, Livieri 2007, Eads 2009), and other members of genus Mustela have shown selection for areas of dense prey in the wild (e.g., European polecat [Mustela putorius], Lode 1996; stoat [Mustela erminea], Cuthbert and Sommer 2002; long-tailed weasel [Mustela frenata], Gehring and Swihart 2004). 
Another plausible explanation for use of average burrow densities by Vermejo kits is that captive-born ferrets might need an adjustment period longer than 2 months to establish habitat preferences in the wild or to learn their new habitat and apply innate preferences. The fine-scale burrow densities where ferrets were observed might have trended toward average available densities by chance as ferrets explored their novel surroundings. Furthermore, early autumn might not be the time of year in which young ferrets need high-quality habitat; the breeding season has not commenced (Richardson et al. 1987) and, due to their age, female kits do not have dependent young (but see Carlson 1993, Biggins et al. 2006b, Jachowski 2007, Livieri 2007, and Eads 2009 for selection of high-density areas by adults). Perhaps ferret kits were adjusting to the wild throughout preconditioning at Vermejo, and perhaps procuring and defending quality habitat was not vital enough during this period to override exploratory behavior.

Wild preconditioning on a prairie dog colony, as performed at Vermejo, is intended to provide naïve, captive-born kits an opportunity to learn wild behaviors. The 2007 kits were released at an average of 85.4 days of age. Because of a presumably innate tendency to disperse shortly after release, kits had little time with their dams in the wild to learn normal behavior patterns before independence from the family unit (Vargas and Anderson 1998). Dams had spent time with previous litters in outdoor pens. Time with dams was further reduced because most dams (5 of 6 ) at Vermejo disappeared within 11 nights of release (Chipault 2010).

In addition to lack of guidance by dams during wild preconditioning, being held in indoor cages during potentially critical stages of development ( $\sim 60-90$ days for prey preference-Vargas and Anderson 1996; <60 days old-Biggins et al. 1998) might have made it more difficult for kits to adjust to a natural environment. Newly released ferret kits $(\sim 120$ days old) without conspecific competitors selected high burrow density habitats during September-November (Biggins et al. 2006b), but 55 of the 71 (Biggins et al. 1998) ferrets had been preconditioned in quasinatural environments before release. Only 18 of the 139 (Biggins et al. 1999) ferrets that used available burrow densities (Carlson 1993) had been pre- conditioned in outdoor pens before their release at $\sim 120$ days old. The pattern of habitat use by Vermejo ferrets could have been due, in part, to the release of kits without prior experience in outdoor conditioning pens, which might have resulted in reduced hunting abilities (Vargas and Anderson 1998), reduced predator avoidance skills (Miller et al. 1990), and reduced overall survival in the wild (Biggins et al. 1998, 1999). If the kits released at Vermejo had developed at an early age in a quasinatural environment, perhaps the expected trends in habitat use would have been observed.

Exposure of ferrets to natural environs at an early age is optimal; however, constraints on time, money, and space within the blackfooted ferret captive-breeding program are genuine (Lockhart et al. 2006), and beginning ferret preconditioning (wild or pen) at $\sim 90$ days of age is probably superior to no preconditioning (Vargas et al. 1998). Translocating wild-born animals has been promising for ferret recovery (Biggins et al. 2006b, 2011) and for recovery of other reintroduced species (Griffith et al. 1989), but there are currently only 2 populations from which excess wildborn ferrets have been removed. Therefore, captive-born ferrets account for $\sim 80 \%$ of the ferrets reintroduced each year (T.M. Livieri, Prairie Wildlife Research, personal communication). It may not be appropriate to consider the ferret behaviors observed at Vermejo in 2007 as normal, especially because Vermejo kits were released at $\sim 85$ days of age rather than the more common $\sim 120$ days of age. However, observations at Vermejo might represent how other newly released ferrets (often young-of-the-year released in autumn) with a similar history of captivity (often indoor cages until 90 days of age) would respond to conditions in the wild.

The 7 colonies and wards inhabited by ferrets in this study had a wide range of available prairie dog burrow densities (36.2-131.0 burrows $\cdot$ ha $^{-1}$, Fig. 3), and burrow densities were positively correlated with prairie dog densities (Chipault 2010). This wide range of refuge and prey densities might have implications for population dynamics of newly released ferrets. Colonies with high burrow densities could potentially enhance ferret survival and productivity rates. For example, in this study, proportionately more ferrets released in high burrow density areas were recaptured at the end 
of the preconditioning period than those released in low density areas (Chipault 2010). Unpublished data suggest a positive correlation between ferret productivity and burrow density (mentioned in Biggins et al. 2006c). Ferrets might maintain smaller home ranges in high-quality habitat (e.g., Cuthbert and Sommer 2002, Gehring and Swihart 2004, Jachowski 2007). Furthermore, releasing ferrets on colonies with high burrow densities might encourage fidelity; if ferrets travel between colonies, their probability of survival is thought to decrease because prey and refugia are scarce off-colony (Biggins et al. 1998). Thus, releasing ferrets onto colonies with high burrow densities might increase reintroduction success.

Spatial statistics proved imperative for this relatively small sampling of spatially dependent data. Trends in data that might have been deemed significant via classic statistical tests were not significant after accounting for spatial autocorrelation. Standard errors were underestimated in classical models (Bonham and Reich 1999, Hoeting 2009). When geographically close locations had similar ferret-used burrow densities, each location carried less information than truly independent locations would. In this study, spatial statistics helped account for underlying trends in burrow distributions on prairie dog colonies (Jachowski et al. 2008) and for habits of individual ferrets, so that a suite of locations from one ferret did not unduly influence the statistical outcome. Because many studies on imperiled species have small sample sizes and spatially explicit data, spatial statistics should be used to gain information while reducing type I errors.

The process of selecting habitat might be different for captive-born individuals adjusting to a natural environment than for wild-born animals. It is important in all reintroduction efforts to determine how animals behave upon release into native habitat and then to establish ways to facilitate the transition to maximize survival and productivity. While it is inappropriate to generalize the specific results from this study of a single cohort of ferrets, it is apparent that monitoring the behavior of animals that are being returned to the wild, during the time of year that releases typically occur and with the stock of animals typically released, is relevant to the recovery of all reintroduced species.

\section{ACKNOWLEDGMENTS}

This research was funded by the Turner Endangered Species Fund; we thank Mike Phillips and Joe Truett of the Fund for their support and Larry Temple for assistance in the field. We also thank the staff of the Vermejo Park Ranch, especially ranch manager Mark Kossler. We are grateful to the numerous volunteers who helped spotlight for black-footed ferrets during this study. Credit is due to Paul Marinari and the rest of the staff at the National Black-footed Ferret Conservation Center. We thank Kristy Bly and Shaun Grassel for reviewing this manuscript. Any use of trade, product, or firm names is for descriptive purposes only and does not imply endorsement by the U.S. federal government.

\section{Literature Cited}

Biggins, D.E., J.L. Godbey, L.R. Hanebury, B. Luce, P.E. Marinari, M.R. Matchett, and A. Vargas. 1998. The effect of rearing methods on survival of reintroduced black-footed ferrets. Journal of Wildlife Management 62:643-653.

Biggins, D.E., J.L. Godbey, B.M. Horton, and T.M. LIVIERI. 2011. Movements and survival of black-footed ferrets associated with an experimental translocation in South Dakota. Journal of Mammalogy 92:742-750.

Biggins, D.E., J.L. Godbey, M.R. Matchett, L.R. Hanebury, T.M. Livieri, AND P.E. Marinari. 2006a. Monitoring black-footed ferrets during reestablishment of free-ranging populations: discussion of alternative methods and recommended minimum standards. Pages 155-174 in J.E. Roelle, B.J. Miller, J.L. Godbey, and D.E. Biggins, editors, Recovery of the black-footed ferret: progress and continuing challenges. U.S. Geological Survey Scientific Investigations Report 2005-5293, Fort Collins, CO.

Biggins, D.E., J.L. Godbey, M.R. Matchett, and T.M. Livieri. 2006b. Habitat preferences and intraspecific competition in black-footed ferrets. Pages 129 140 in J.E. Roelle, B.J. Miller, J.L. Godbey, and D.E. Biggins, editors, Recovery of the black-footed ferret: progress and continuing challenges. U.S. Geological Survey Scientific Investigations Report 2005-5293, Fort Collins, CO.

Biggins, D.E., J.M. Lockhart, and J.L. Godbey. 2006c. Evaluating habitat for black-footed ferrets: revision of an existing model. Pages 143-150 in J.E. Roelle, B.J. Miller, J.L. Godbey, and D.E. Biggins, editors, Recovery of the black-footed ferret: progress and continuing challenges. U.S. Geological Survey Scientific Investigations Report 2005-5293, Fort Collins, CO.

Biggins, D.E., B.J. Miller, L.R. Hanebury, B. Oakleaf, A.H. Farmer, R. Crete, and A. Dood. 1993. A technique for evaluating black-footed ferret habitat. Pages 73-88 in J.L. Oldemeyer, D.E. Biggins, B.J. Miller, and R. Crete, editors, Management of prairie dog complexes for the reintroduction of the black-footed 
ferret. U.S. Fish and Wildlife Service Biological Report 13, Washington, DC.

Biggins, D.E., M. Schroeder, S. Forrest, and L. RiCHARDSON. 1985. Movements and habitat relationships of radio-tagged black-footed ferrets. Pages 11.111.17 in S.H. Anderson and D.B. Inkley, editors, Black-footed Ferret Workshop Proceedings. Wyoming Game and Fish Department, Cheyenne, WY.

Biggins, D.E., J.G. Sidle, D.B. Seery, and A.E. Ernst. 2006d. Estimating the abundance of prairie dogs. Pages 94-107 in J.L. Hoogland, editor, Conservation of the black-tailed prairie dog: saving North America's western grasslands. Island Press, Washington, DC.

Biggins, D.E., A. Vargas, J.L. Godbey, and S.H. AnderSON. 1999. Influence of prerelease experience on reintroduced black-footed ferrets (Mustela nigripes). Biological Conservation 89:121-129.

BonHaM, C.D., AND R.M. REICH. 1999. Influence of spatial autocorrelation on a fixed-effect model used to evaluate treatment of oil spills. Applied Mathematics and Computation 106:149-162.

CARLSON, J.C. 1993. Release box use and habitat selection by black-footed ferrets (Mustela nigripes) released into Shirley Basin, Wyoming. Master's thesis, University of Wyoming, Laramie, WY.

Chapin, T.G., D.J. Harrison, and D.M. Phillips. 1997. Seasonal habitat selection by marten in an untrapped forest reserve. Journal of Wildlife Management 61: 707-717.

Chipautt, J.G. 2010. Fine-scale habitat use by black-footed ferrets (Mustela nigripes) released on black-tailed prairie dog (Cynomys ludovicianus) colonies in New Mexico. Master's thesis, Colorado State University, Fort Collins, CO.

CoOper, A.B., AND J.J. Millspaugh. 2001. Accounting for variation in resource availability and animal behavior in resource selection studies. Pages 243-274 in J.J. Millspaugh and J.M. Marzluff, editors, Radio tracking and animal populations. Academic Press, New York, NY.

Cuthbert, R., AND E. Sommer. 2002. Home range, territorial behaviour and habitat use of stoats (Mustela erminea) in a colony of Hutton's shearwater (Puffinus huttoni), New Zealand. New Zealand Journal of Zoology 29:146-160.

CZaplewski, R.L., R.M. REICH, and W.A. BECHTOLD. 1994. Spatial autocorrelation in growth of undisturbed natural pine stands across Georgia. Forest Science 40: 314-328.

EADS, D.A. 2009. Evaluation and development of blackfooted ferret resource selection models. Master's thesis, University of Missouri, Columbia, MO.

Fagerstone, K.A., and B.E. Johns. 1987. Transponders as permanent identification markers for domestic ferrets, black-footed ferrets, and other wildlife. Journal of Wildlife Management 51:294-297.

Forrest, S.C., T.W. Clark, L. Richardson, and T.M. CAMPBELL III. 1985. Black-footed ferret habitat: some management and reintroduction considerations. BLM Wildlife Technical Bulletin 2, Cheyenne, WY.

Gehring, T.M., and R.K. Swihart. 2004. Home range and movements of long-tailed weasels in a landscape fragmented by agriculture. Journal of Mammalogy 85:79-86.

Griffith, B., J.M. SCotT, J.W. Carpenter, and C. ReEd. 1989. Translocation as a species conservation tool: status and strategy. Science 245:447-480.
Hoeting, J.A. 2009. The importance of accounting for spatial and temporal correlation in analyses of ecological data. Ecological Applications 19:574-577.

HoogLAND, J.L. 1995. Black-tailed prairie dog: social life of a burrowing mammal. University of Chicago Press, Chicago, IL.

JACHOWSKI, D.S. 2007. Resource selection by black-footed ferrets in relation to the spatial distribution of prairie dogs. Master's thesis, University of Missouri, Columbia, MO.

JACHOWSKI, D.S., AND J.M. LOCKHART. 2009. Reintroducing the black-footed ferret Mustela nigripes to the Great Plains of North America. Small Carnivore Conservation 41:58-64.

Jachowski, D.S., J.J. Millspaugh, D.E. Biggins, T.M. Livieri, AND M.R. MatchetT. 2008. Implications of black-tailed prairie dog spatial dynamics to blackfooted ferrets. Natural Areas Journal 28:14-25.

Lichstein, J.W., T.R. Simons, S.A. Shriner, and K.E. FranZREB. 2002. Spatial autocorrelation and autoregressive models in ecology. Ecological Monographs 72:445-463.

LiviERI, T.M. 2007. Black-footed ferret spatial use of prairie dog colonies in South Dakota. Master's thesis, University of Wisconsin, Stevens Point, WI.

LOCKHART, J.M., E.T. ThORNE, AND D.R. GOBER. 2006. A historical perspective on recovery of the black-footed ferret and the biological and political challenges affecting its future. Pages 6-19 in J.E. Roelle, B.J. Miller, J.L. Godbey, and D.E. Biggins, editors, Recovery of the black-footed ferret: progress and continuing challenges. U.S. Geological Survey Scientific Investigations Report 2005-5293, Fort Collins, CO.

LODE, T. 1996. Conspecific tolerance and sexual segregation in the use of space and habitats in the European polecat. Acta Theriologica 41:171-176.

Long, D.H., K. Bly-Honness, J.C. Truett, and D.B. SEERY. 2006. Establishment of new prairie dog colonies by translocation. Pages 188-209 in J.L. Hoogland, editor, Conservation of the black-tailed prairie dog: saving North America's western grasslands. Island Press, Washington, DC.

Miller, B., D. Biggins, C. Wemmer, R. Powell, L. Calvo, L. Hanebury, and T. Wharton. 1990. Development of survival skills in captive-raised Siberian polecats (Mustela eversmanni) II: predator avoidance. Journal of Ethology 8:95-104.

Miller, B., G. Ceballos, and R. Reading. 1994. The prairie dog and biotic diversity. Conservation Biology 8:677-681.

Moran, P.A.P. 1950. Notes on continuous stochastic phenomena. Biometrika 37:17-23.

REICH, R.M., AND C.D. Bonham. 2001. Spatial analysis of grazed white bursage in the Lake Mead National Recreational Area, Nevada, USA. Grassland Science 47:128-133.

Richardson, L., T.W. Clark, S.C. Forrest, and T.M. CAMPBELl III. 1987. Winter ecology of black-footed ferrets (Mustela nigripes) at Meeteetse, Wyoming. American Midland Naturalist 117:225-239.

SheEts, R.G., R.L. Linger, and R.B. DAhLgRen. 1972. Food habits of two litters of black-footed ferrets in South Dakota. American Midland Naturalist 87: 249-251.

SLOUGH, B.G. 1994. Translocation of American martens: an evaluation of factors in success. Pages 165-178 in S.W. Buskirk, A.S. Harestad, M.G. Raphael, and 
R.A. Powell, editors, Martens, sables, and fishers: biology and conservation. Cornell University Press, Ithaca, NY.

StampS, J.A., AND R.R. Swaisgood. 2007. Someplace like home: experience, habitat selection and conservation biology. Applied Animal Behaviour Science 102: 392-409.

Vargas, A., and S.H. ANDERson. 1996. Effects of diet on captive black-footed ferret (Mustela nigripes) food preference. Zoo Biology 15:105-113.

1998. Ontogeny of black-footed ferret predatory behavior towards prairie dogs. Canadian Journal of Zoology 76:1696-1704
Vargas, A, M. Lockhart, P. Marinabi, and P. Gober. 1998. Preparing captive-raised black-footed ferrets Mustela nigripes for survival after release. The Dodo: Journal of the Jersey Wildlife Preservation Trust 34:76-83.

Received 30 April 2011 Accepted 13 February 2012 